to shell fire, but at the same time it reduces speed and mobility. In the same way animal defences may work well against one kind of attacker but be much less effective against others. The king cobra, for example, is venomous enough to kill an elephant, but is itself killed on occasions by the mongoose with its superior agility.

A closely related idea is that every defensive adaptation has a "cost" which might, for example, be measured in terms of energy that could otherwise be channelled into reproduction. One of the most convincing pieces of evidence for the cost of anti-predator adaptations comes

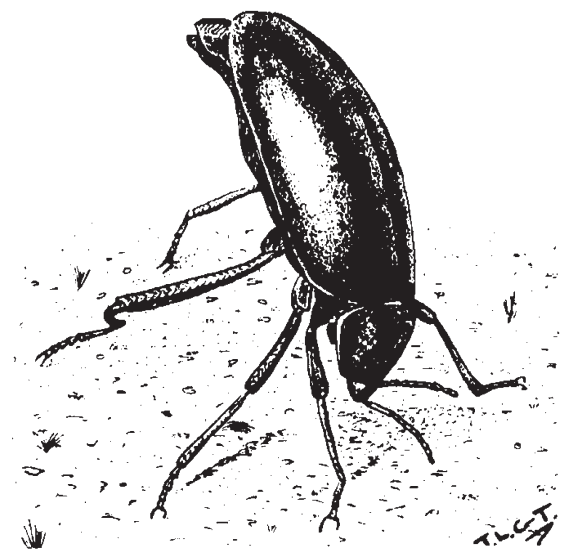

Chemical defence: when disturbed, Eleodes sprays a secretion at the attacker from its abdomen.

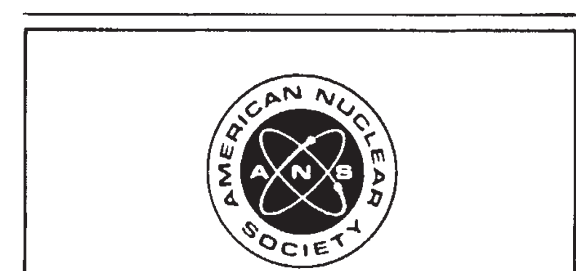

\section{AMERICAN NUCLEAR SOCIETY'S PUBLICATIONS}

\section{Complete Nuclear \\ Publications and}

Services Worldwide.

$$
\begin{aligned}
& \text { Inquire about specific } \\
& \text { interests. }
\end{aligned}
$$

For Free Publications and Services Catalog, contact:

American Nuclear Society 555 N. Kensington Avenue La Grange Park, IL 60525 U.S.A.

Circle No. 02 on Reader Enquiry Card. from the study of chemical defences in plants (and is therefore not discussed by Cloudsley-Thompson). R. G. Cates (Ecology 56, 391-400; 1975) has shown that wild ginger plants (Asarum caudatum) in places where slugs are common channel more energy into chemical defence (they taste nastier) at the expense of seed production and growth than do plants of the same species where there is little grazing pressure.

The book touches on some issues without trying to discuss them in their full complexity. For example, in the discussion of Müllerian mimicry (mimicry in which several unpalatable species share the same colour patterns) Cloudsley-Thompson presents the conventional argument that a shared colour pattern reduces the chances that an individual will be killed by a predator in the process of learning to associate colour with distastefulness; the larger the pool of similarly coloured prey individuals, the smaller the chance that any one of them will be killed. While this argument seems to be correct, it leads one to expect that all unpalatable species living in the same habitat should share the same warning colour patterns. In fact it is known that neotropical butterflies, for example, form several different Müllerian mimicry complexes within the same habitat (C. Papageorgis Am. Sci. 73, 522-53; 1975).

The mechanism of evolution of warning coloration is also glossed over, with no mention of R. A. Fisher's suggestion that it might have arisen through kin selection.

However it would be churlish to criticize a popular book for not exploring recondite details. The main aim of CloudsleyThompson's book is to entertain and stimulate the reader. In this it succeeds. $[$ ?

John R. Krebs is a Lecturer in the Edward Grey Institute of Field Ornithology, Department of Zoology, University of Oxford.

\title{
Animals for the coffee table and student
}

\section{Bryan Turner}

The Complete Encyclopedia of the Animal World. Edited by David M. Burn. Pp. 400 . (Octopus: 1980.) £12.95, \$17.98.

THE diversity of animals, the sheer numbers of species, and the richness of their differing forms and functions has always fascinated people. It attracts the curious layman and for biologists begs answers to questions of "how?" and "why?". Although this book has been written and designed to adorn the coffee tables of the general public, students of zoology will find much to interest them. The book is of a higher intellectual standard than that customarily associated with this sort of glossy volume, in part due to the impressive list of contributors. Each section has been written by an acknowledged expert in that particular field. Skilful editing has successfully combined the many and varied styles of the contributors in a way that makes section to section differences unobtrusive.

The text is complemented by a beautiful series of colour photographs and novel illustrations. Although most of the illustrations are useful, some are confusing: for instance, in a figure of the distribution of the geological plates of the Earth's crust the key is absent so that the variously coloured boundaries are meaningless. Perhaps somewhat more important than minor irritants of this nature is the discussion on the links between the chordates and the non-chordates (essentially but not precisely equivalent to the vertebrates and invertebrates). Here the widely held ideas of a link involving the hemichordate acorn worms are dismissed and a new but little accepted theory involving the fossil calcichordates is expounded. In a general text such as this the most widely accepted views of the experts should surely take precedence, and any new and highly controversial ideas take second place.

The main part of the book is a catalogue of the different groups of animals which is sandwiched between chapters on special aspects of animal life. There are introductory chapters on ecology, in which the biologists" "how?" and "why?" questions are briefly considered, and on taxonomy explaining the classificatory process. This latter section is introduced by a full colour photograph of the book's editor in the guise of a lepidopteran taxonomist supposedly illustrating the qualities of "Patience, experience and a good eye" perhaps a book on brass instruments will be next! Other specialist chapters include such topics as locomotion, migration, senses, associations, endangered species and a useful section on the major zoos and national parks of the world. The foreword, curiously by David Bellamy, the "Botanic Man", is accompanied by a picture of him riding a tortoise. To ensure that we recognize him, the usually sufficient facial characteristics have been supplemented by those other well-aired taxonomic features — the hairy legs!

These asides apart, this book does represent a good, balanced and informative account of the immense variety of animal life. Although unable in 400 pages to live up to its title "Complete", it is none the less a very creditable contribution from the Octopus stables.

Bryan Turner is a Lecturer in Zoology at King's College, London. 